\title{
First Trimester Anomaly Scan-The Last Redoubt Won: Open Spina Bifida
}

\author{
${ }^{1}$ Stefania Tudorache, ${ }^{2}$ Iliescu Dominic Gabriel, ${ }^{3}$ Adina Turcu, ${ }^{4}$ Maria Florea, ${ }^{5}$ Roxana Drăguşin, \\ ${ }^{6}$ Liliana Novac, ${ }^{7}$ Cernea Nicolae, ${ }^{8}$ Daniela Cernea
}

\begin{abstract}
Open spina bifida (OSB) is a non-lethal fetal anomaly, yet often leads to severe disability. Most cases of open spina bifida are detected at the second trimester fetal anomaly ultrasound scan. The 11 to 13 weeks of amenorrhea scan evolved over the last 20 years from essentially a dating scan, to a genetic scan, and recently to one which includes, in addition to the genetic markers, a basic checklist for examination of the whole fetal anatomy. The direct visualization of the spine at the first trimester (FT) scan remained difficult, despite the wider use of high-resolution ultrasound machines and the volumetric approach. Thus, indirect intracranial morphological markers for OSB were proposed to diagnose this neural tube defect.

The present review aims to describe the specific anatomical feature of the spine and the posterior brain, both on parasagittal and on axial planes, recently proposed for the early detection of OSB.

Specialists involved in the prenatal diagnosis will eventually elaborate in the future a screening protocol for OSB in the FT of pregnancy, using the most valuable and easy to obtain marker, in a single $2 \mathrm{D}$ plane.

The offer of an early diagnosis of possible severe anomalies, such as OSB, is a tool enhancing the autonomy of the pregnant woman.
\end{abstract}

Keywords: Open spina bifida, First trimester, Anomaly scan, Posterior brain.

How to cite this article: Tudorache $S$, lliescu DG, Turcu A, Florea M, Drăguşin R, Novac L, Nicolae C, Cernea D. First

${ }^{1-3}$ Senior Lecturer, ${ }^{4}$ Student and Resident Trainee, ${ }^{5}$ Resident Trainee, ${ }^{6,7}$ Professor and Chairman, ${ }^{8}$ Professor

1,2 Department of Obstetrics and Gynecology, Prenatal Diagnostic Unit, University of Medicine and Pharmacy, Craiova, Romania

${ }^{3}$ Pharmacist Doctor, Discipline Management and Public Health University of Medicine and Pharmacy, Craiova, Romania

${ }^{4,5}$ Prenatal Diagnostic Unit, University of Medicine and Pharmacy, Craiova, Romania

${ }^{6}$ The 2nd Department of Obstetrics and Gynecology, Prenatal Diagnostic Unit, University of Medicine and Pharmacy, Craiova Romania

${ }^{7}$ The 1st Department of Obstetrics and Gynecology, Prenatal Diagnostic Unit, University of Medicine and Pharmacy, Craiova Romania

${ }^{8}$ Department of Anesthesiology and Intensive Care, University of Medicine and Pharmacy, Craiova, Romania

Corresponding Author: Stefania Tudorache, Senior Lecturer Department of Obstetrics and Gynecology, Prenatal Diagnostic Unit, University of Medicine and Pharmacy, Craiova, Romania e-mail: stefania.tudorache@gmail.com
Trimester Anomaly Scan-The Last Redoubt Won: Open Spina Bifida. Donald School J Ultrasound Obstet Gynecol 2015;9(1):80-90.

Source of support: Nil

Conflict of interest: None declared.

\section{INTRODUCTION}

\section{The First Trimester Anomaly Scan}

Maternal-fetal medicine is a nowadays' reality. It is the branch of obstetrics that focuses on the medical and surgical management of pathologic pregnancies. This science is promoting equality between the two patients: the mother and the fetus. Management includes monitoring and treatment: comprehensive ultrasound, chorionic villus sampling, genetic amniocentesis, and fetal surgery or treatment.

The prenatal diagnosis became an integral part of obstetric modern care and is standard care in most European countries. The ultrasound (US) examination is the single most important noninvasive technique used for the fetal study. In addition, we are witnessing a long-term safety record of pregnancy ultrasound imaging ${ }^{1}$, thus an extensive use in modern obstetric care.

Since 2011, when the new, inverted pyramid of prenatal care was proposed, ${ }^{2}$ the 12 weeks scan became the pillar of obstetric care. Examining the fetus at this gestational age (GA) rapidly became the most important scan throughout the whole pregnancy.

We already have proof that the 12 weeks of amenorrhea (WA) scan allow the most performant screen for chromosomal anomalies (nuchal translucency-NT being the most important marker), using the combined test. ${ }^{3}$ Moreover, at this GA, due to ever-growing resolution of the system used, we are able to detect the vast majority of major fetal congenital structural anomalies. ${ }^{4-17}$ Recent literature reports high detection rates for all fetal systems' major anomalies, including, more recently, isolated congenital heart diseases.

Nowadays, efforts are made to develop algorithms based on combinations of maternal characteristics, early ultrasound findings and biochemical testing of maternal blood. This approach proved efficient in predicting most major aneuploidies, ${ }^{2}$ miscarriage and fetal death, ${ }^{18,19}$ 
preterm delivery, ${ }^{20,21}$ preeclampsia, ${ }^{22}$ gestational diabetes, $^{23-25}$ fetal growth restriction ${ }^{26}$ and macrosomia. ${ }^{27}$ Recently, international leading societies, as ISUOG (International Society of Ultrasound in Obstetrics and Gynecology), ${ }^{28}$ NICE (National Institute for Clinical Excellence) ${ }^{29}$ and ACOG (American College of Obstetricians and Gynecologists) ${ }^{30}$ have issued guidelines on routine prenatal care recommending that all pregnant women should be offered the first trimester (FT) ultrasound scan.

Early detection of fetal malformations offers the possibility of an earlier and safer termination of pregnancy (TOP) in cases with severe structural abnormalities detected, with less economic and emotional costs. ${ }^{31}$ This will probably have an impact in perinatal demographic figures, because major fetal abnormalities accounted until recent for $25 \%$ of neonatal deaths and usually lead to longterm disabilities and high socioeconomic costs. ${ }^{32}$

Still, an extensive assessment of the fetal anatomy at the FT scan requires appropriate training of sonographers and high-resolution equipment. This type of examination may be dragged down by low availability of human resources and material endowments, local medical practice and legal considerations and insurance-related cost reimbursements.

Regarding the fetal morphologic assessment, the current policy of most healthcare systems is to offer routinely a transabdominal ultrasound examination performed at $18+0-23+6 \mathrm{WA},{ }^{28}$ because some structural anomalies may develop at later stages of pregnancy or may develop from pathophysiological process undetectable in the FT. Thus, the standard second trimester (ST) scan cannot be replaced, and still represents the gold standard test against witch the FT assessment should be compared. ${ }^{33-37}$

Gradually, the 11-13 WA scan evolved over the last 20 years from essentially a dating and genetic scan to one which also includes a basic checklist for examination of the whole fetal anatomy. Diseases that are either lethal or are associated with possible survival and severe immediate or long-term morbidity ${ }^{4-17,38}$ are usually accessible at this GA. Common sense, supported by objective studies, tells us that parents want to know about any fetal problems as early in pregnancy as possible. ${ }^{39}$

Using a complete morphology protocol is a prerequisite for high detection rates of major anomalies, which can reach around $80 \% .{ }^{10-17}$ This figure is not far from the efficiency of ST anomaly scan. ${ }^{28,33,37,40}$ A systematic review on the ST anomaly scan effectiveness reported that about $45 \%$ of the major anomalies were detected routinely, ${ }^{41}$ with large differences between studies in detection rates which ranged from 15 to $85 \%$, and also large differences in overall detection rates according to the type of fetal anomaly. This variation depends on the type of studied malformations, the follow-up method and the extension of the scan protocols.

\section{The First Trimester Central Nervous System Morphological Assessment}

Central nervous system (CNS) malformations are some of the most common congenital abnormalities (10 per 1000 live births, compared to heart at 8 per 1000, kidneys at 4 per 1000 , and limbs at 1 per $1000^{44}$ ). The FT scan was reported recently with a higher degree of detection for major CNS anomalies - 53-69\%. ${ }^{17,42}$

On the other hand, there are important limitations in the prenatal diagnostic of CNS abnormalities ultrasound, ${ }^{16,43}$ as most of the congenital anomalies of the nervous system are undetectable during the FT evaluation. They may be associated only with subtle findings in early gestation as the brain continues to develop during pregnancy and into the neonatal period. Agenesis of corpus callosum, microcephaly and hydrocephaly usually cannot be detected in the FT, and sometimes these findings are apparent only in late stages of pregnancy. Also, some cerebral lesions are not due to defective embryological development but represent the consequence of acquired prenatal or perinatal damage. ${ }^{44-46}$

The most important congenital anomalies of the nervous system concerning prevalence and severity are usually detectable during the FT scan, including holoproencephaly and some neural tube defects (NTDs). The visualization of the falx cerebri, calvaria and head shape are easily achieved in the FT transverse incidence, thus, holoprosencephaly and encephalocele are detectable.

The minimum requirements recommended by the ISUOG Practice Guidelines ${ }^{28}$ for a basic fetal anatomical survey at the end of the FT of pregnancy are two axial planes: the transthalamic (the biparietal diameter - BPD measurement) plane, and the third-ventricle plane, with the demonstration of the symmetric, normal choroid plexuses. Also, about the spine, the mentioned guidelines state that an 'attempt should be made to show intact overlying skin. However, in the absence of obvious anomaly, failure to examine the spine at this time should not prompt further examination earlier than the mid-trimester scan'. In terms of parasagittal fetal face planes, the statement is as it follows: 'It has been proposed that the posterior fossa intracranial translucency can be evaluated between 11 and $13+6$ weeks as a screening test for open neural tube defect, but this is not a standard'. 


\section{Open Spina Bifida-The Importance of the Disease}

Open spina bifida is a nonlethal fetal anomaly. Significant progress has been made in the prevention, diagnosis and treatment of open spina bifida over the past 75 years.

There are two forms of spina bifida cystica (open spina bifida): meningocele (a rare type of spina bifida in which only the membranes protecting the spinal cord herniate through the vertebrae), and myelomeningocele. Myelomeningocele is the most serious form of spina bifida, it accounts for $75 \%$ of cases. Between 70 and $80 \%$ of children with OSB will also develop hydrocephalus. ${ }^{47}$ The condition appears to be caused by a combination of genetic factors and environmental influences. The specific genes and environmental factors are not completely understood..$^{48}$ OSB occurs in approximately 6 per 10,000 births. ${ }^{49}$ Liveborn infants with myelomeningocele have a death rate of approximately $10 \% .{ }^{50}$

Most cases of open spina bifida are detected at the 18+0WA - 20+6 WA fetal anomaly US scan. ${ }^{48}$

Although efforts are made toward new approaches to the fetal treatment of OSB, ${ }^{51,52}$ the management of OSB is only finalized in many European countries (including ours) after birth, when the type and size of the lesion is assessed. The treatment depends upon the position and the severity of the lesion. Most cases of OSB require an operation to repair the neural tube after birth. It is common that some damage to the newborn's nervous system already took place and surgery is not often able to correct all problems. If the child develops hydrocephalus, this also needs to be treated with surgery as increased pressure induced by the excessive fluid can cause brain damage. Surgery involves draining the fluid into the abdomen (a ventriculo-peritoneal shunt). This often needs to be replaced as the child grows because of problems with blockage and infection. ${ }^{53-57}$

The prognosis for babies born with OSB depends on the location, size and extent of the defect and the presence of hydrocephalus, and the range of disability caused is variable. Still, it often leads to severe disability. Children with spina bifida frequently have problems controlling the bladder and bowels functions. In serious cases, the baby may have problems walking or be unable to walk. Hydrocephalus cause learning difficulties. Generally, abnormalities higher on the spine produce a greater risk of paralysis and other debilitating complications. ${ }^{53-57}$

Nowadays, all women are advised to take a supplement of $400 \mathrm{mg}$ of folic acid for at least 3 months before pregnancy and up to the end of the 12th week of pregnancy. ${ }^{58}$ Women who have a family history of NTDs are advised to take a higher dose of $5 \mathrm{mg}$ of folic acid, as this has been shown to reduce their chances or having another baby with an NTD. ${ }^{58}$
Depending on the US findings, additional information from a pediatric team with expertise in the care and management of children with OSB should be offered. If the FT diagnosis is performed, a TOP should be offered following appropriate counselling. Women should be offered the opportunity to discuss the possible implications of continuing or ending their pregnancy. In our country, TOP at maternal request at more than $13+6$ WA for non-lethal diseases such as OSB is illegal, thus the FT anomaly scan is more important than in other European states.

Because early TOP seems to include less risks and less harm for the women (although, of course any TOP because of fetal anomalies is associated with distress and intense psychological morbidity for some), it is comprehensible that women prefer earlier TOP as compared with later.

Some women choose to continue the pregnancy, and these parents will need ongoing care and support. Women who wish to continue their pregnancy should be antenatally referred to the pediatric surgery team who will care for their baby. Ongoing antenatal care involves ultrasound scans to monitor the fetus.

\section{OSB Diagnosis at the End of the FT of Pregnancy -The Limits of the Current Approaches}

The direct visualization of the spine NTDs at the FT scan remained difficult, despite the wider use of high-resolution ultrasound machines. Thus, indirect intracranial morphological markers for open spina bifida were proposed to diagnose this NTD.

Since 1997, when the lemon sign was described at 10 to 14 weeks of amenorrhea, ${ }^{59}$ the US of the fetal head holds promise for the early detection of spina bifida (OSB) at the end of the FT, instead of the fetal spine. At this GA, as said before, the direct diagnosis on the basis of the myelomeningocele remained extremely challenging, due probably to size restrictions.

Posterior brain anomalies, usually having subtle changes, can be yet identified in the parasagittal plane, used for the NT thickness measurement: compression of the fourth ventricle, leading to decrease or disappearance of the normal intracranial translucency (IT) ${ }_{1}^{60-62}$ altered ranges of the brain stem, ${ }^{63}$ nonvisualization of the cisterna magna $^{64,65}$ (changes that give the subjective impression of the caudal displacement of the brainstem), decreased frontomaxillary facial (FMF) angle. ${ }^{66}$

Also, in axial views, the third-ventricle plane offers the measurements of the lateral ventricle area, the diameter of the roof of the third ventricle and the transthalamic plane-the diameter of the aqueduct of Sylvius, significantly decreased, all demonstrating the alteration of intracranial collection of cerebrospinal fluid. ${ }^{67}$ These 
Table 1: 2D planes and 2D markers for fetal CNS morphologic evaluation at the first-trimester ultrasound scan

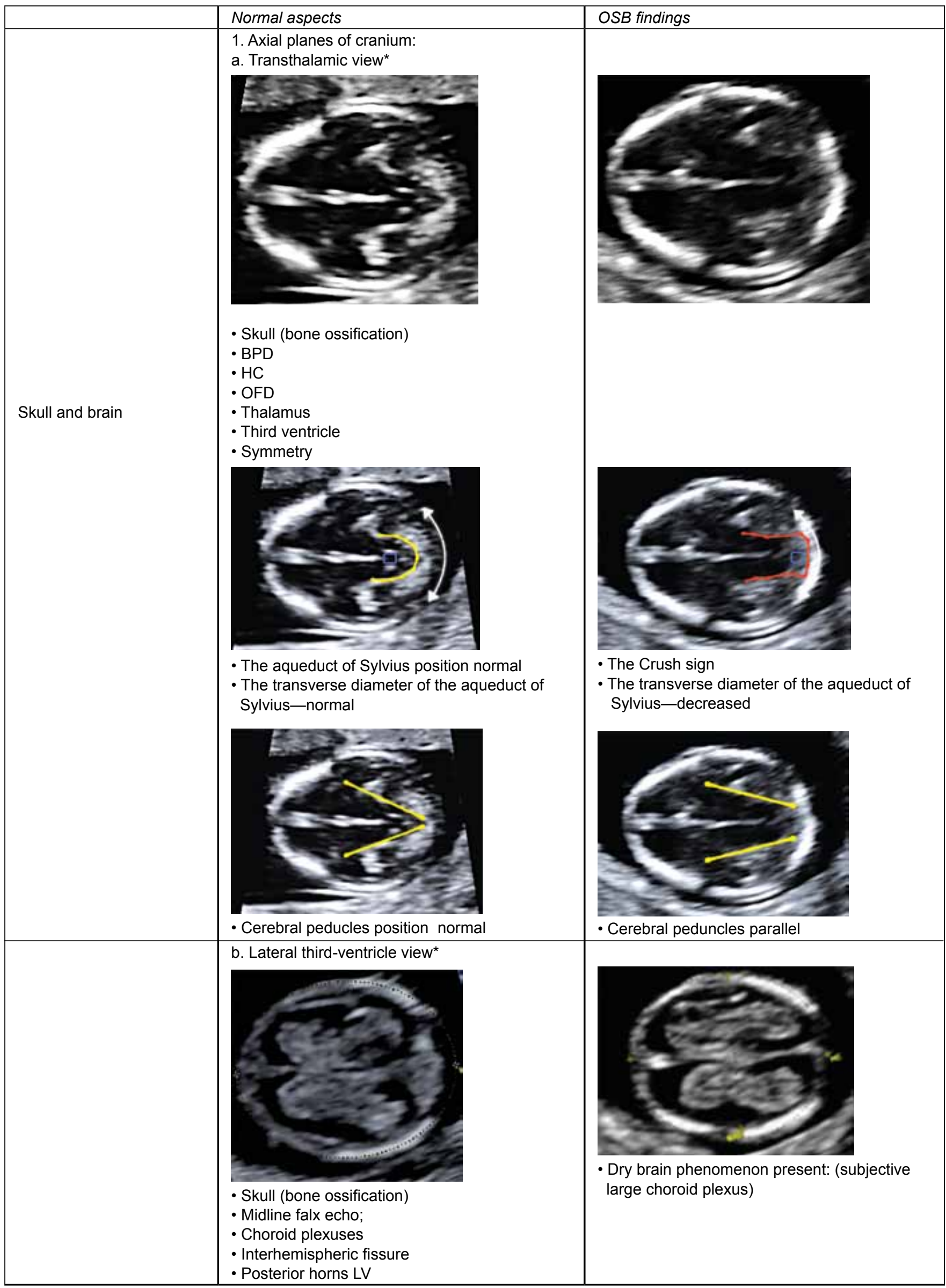

Contd... 


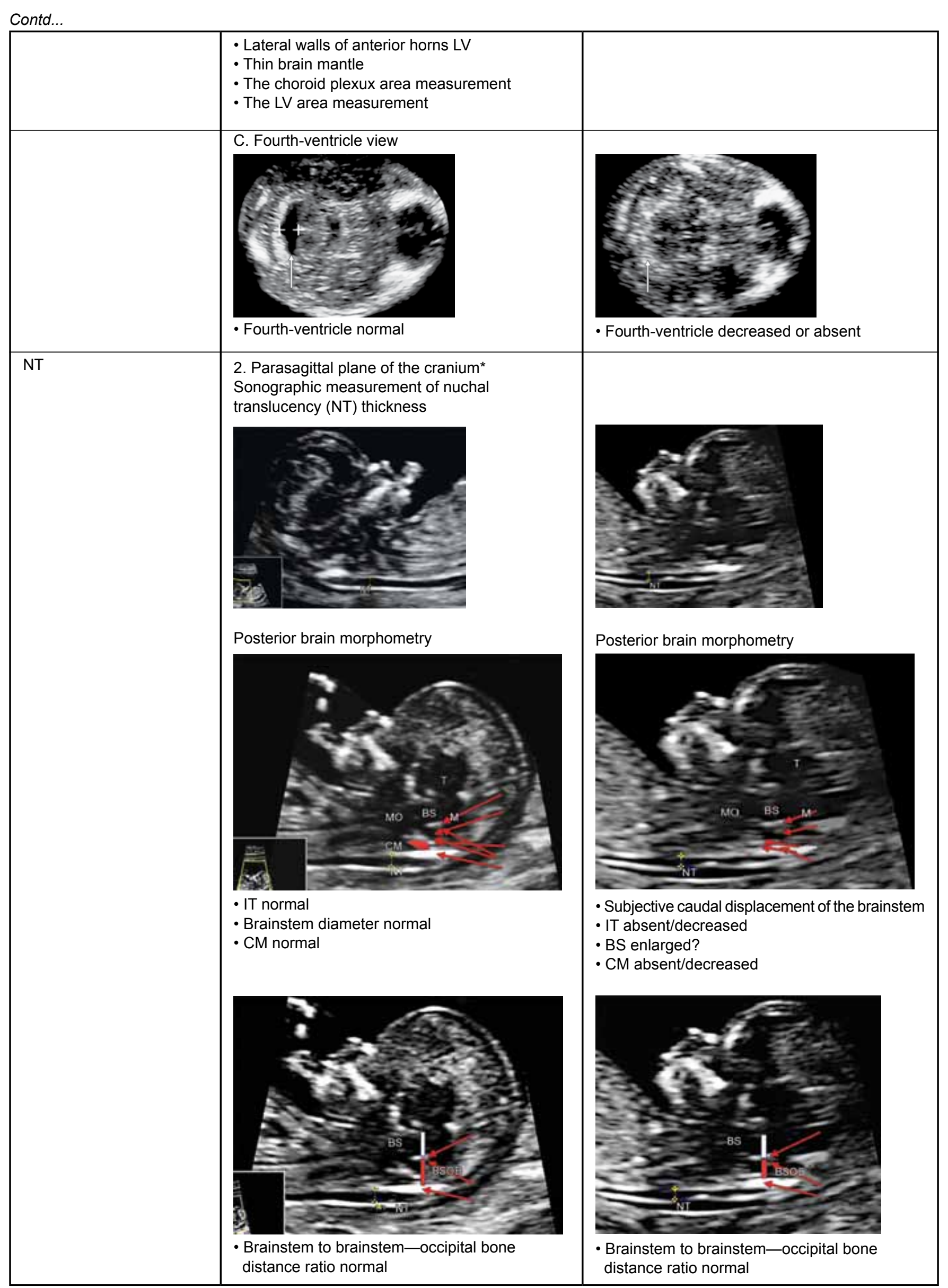

Contd... 


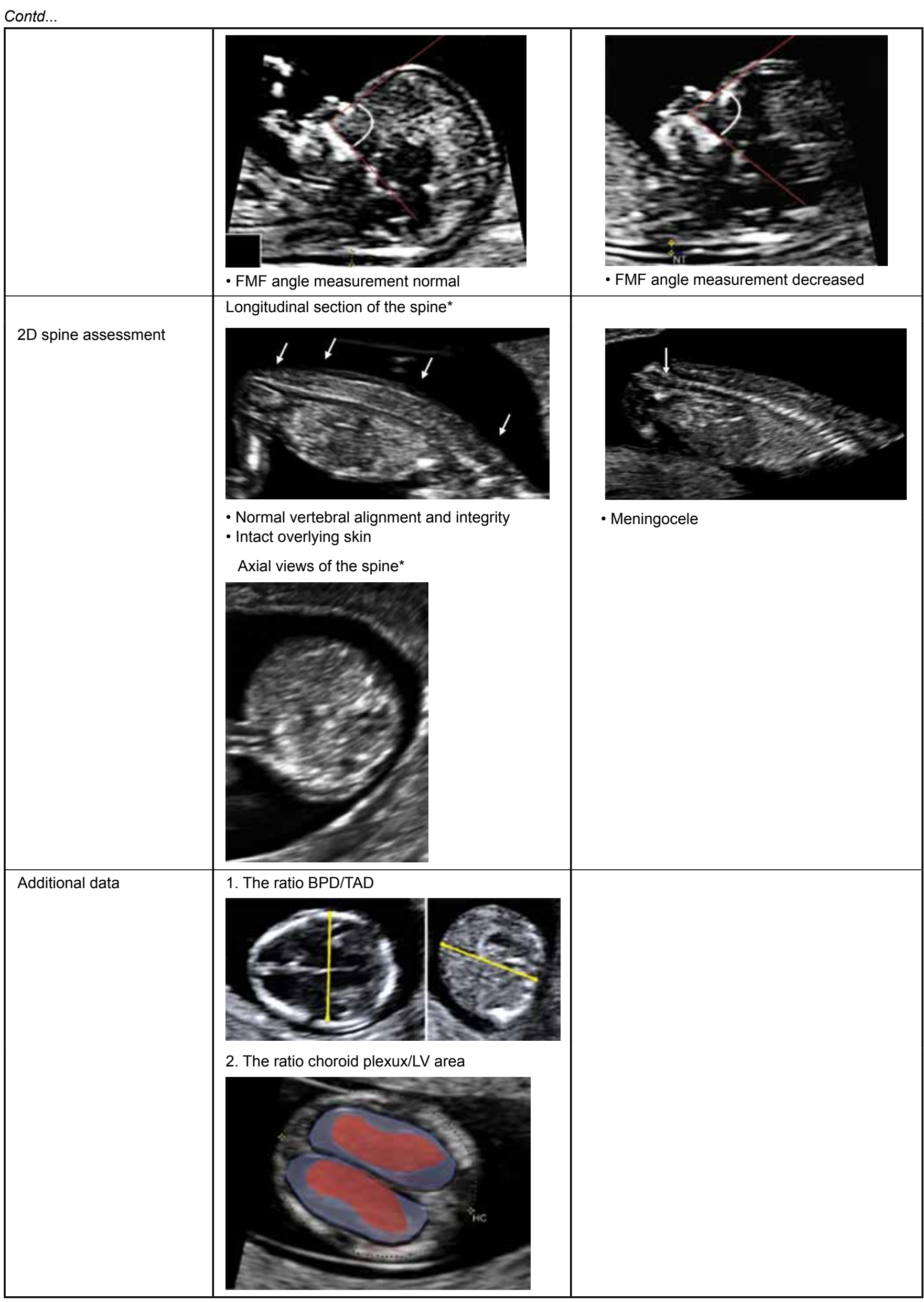


alterations were described as a subjective sign, the 'driedup brain phenomenon'. In the transthalamic axial view, also the 'acorn-shaped head' was described, with the cerebral peduncles appearing parallel to each other, ${ }^{68}$ and more recently, the posterior-caudal displacement of the mesencephalon and its flattening against the occipital bone ('crash sign'). ${ }^{69}$

Moreover, it have been demonstrated that fetuses with OSB have smaller heads, ${ }^{70-72}$ thus have altered intrafetal ratios. $^{73}$

Easy to see, the screening in the FT using only the two axial planes recommended in recent guidelines, without searching for any other marker, will miss virtually all OSB cases, especially if performed by a less experienced observer.

Along with the fetal heart, in terms of FT OSB screening, no protocols are available yet.

In a series of 18 published screening studies ${ }^{4-17,34,74-76}$ reporting on the effectiveness of the first-trimester scan in the diagnosis of fetal major abnormalities, all using a standard screening protocol, we numbered 118110 cases and we collected 5 cases diagnosed, and 34 cases missed. This underlines the difficulties encountered in OSB diagnosis in the FT. On the contrary, it is likely that adding at least a marker for OSB, we will be ending up by diagnosing the majority of cases, since introducing just a simple and reproducible parameter as BPD resulted in detecting half of the cases. ${ }^{70}$

\section{OSB Diagnosis at the End of the FT of Pregnancy -the Future}

In Table 1, we describe the planes that were proposed in searching for markers, and the anatomical features that proved efficiency in the early diagnosis of OSB. We also demonstrate with images the differences between normal cases and OSB cases.

\section{Volumetric Ultrasound}

Three-dimensional (3D) rendering images provide lately an entirely new visual experiences for some examiners and couples owing to the anatomically realistic depiction of normal and abnormal fetal surfaces. However,

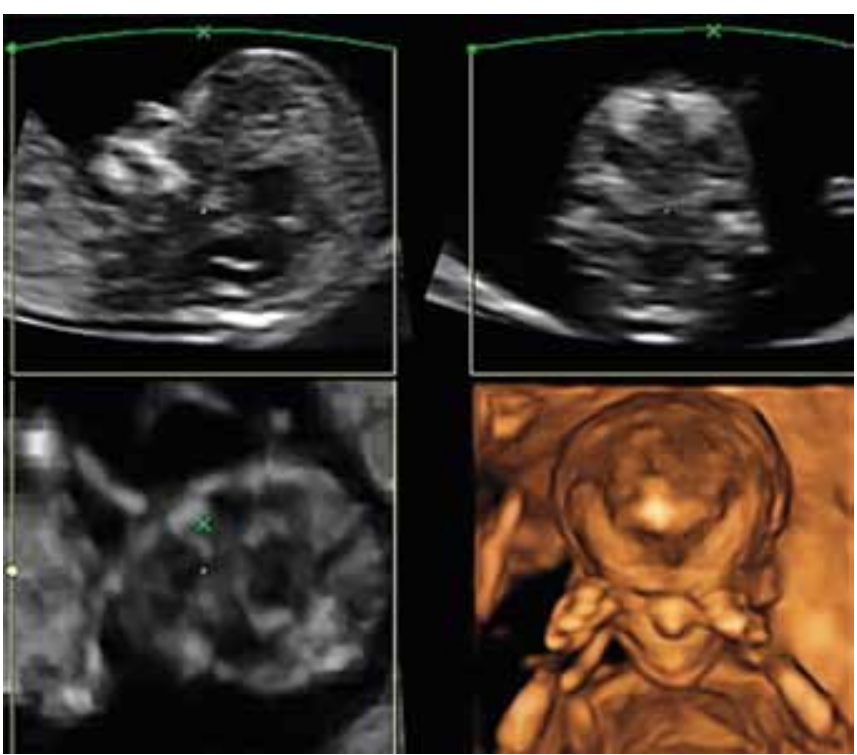

Fig. 1: 3D static acquisition of the fetal head, surface rendering, normal case. The acquisition plane-the sagittal plane

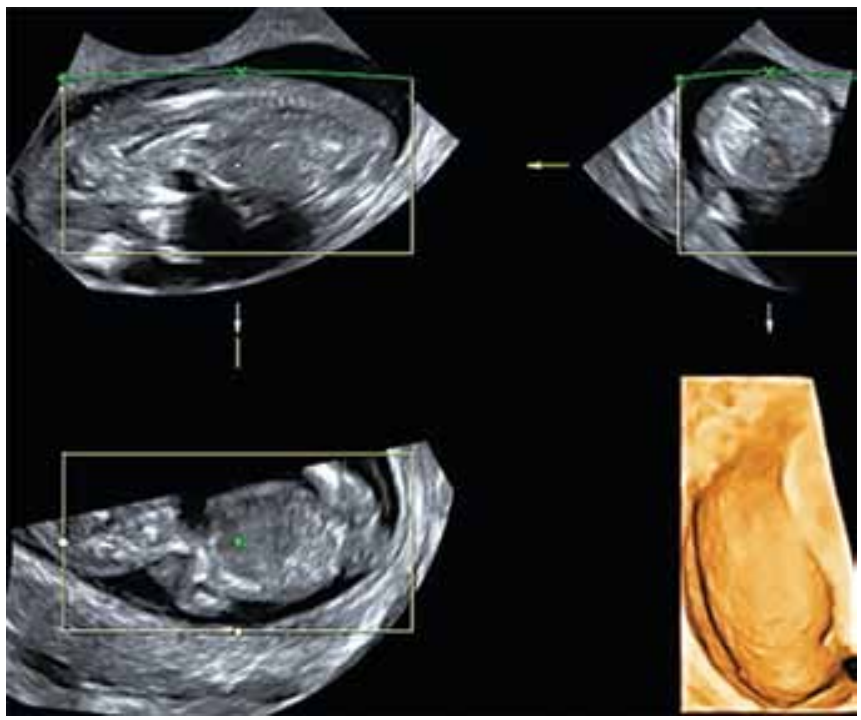

Fig. 2: 3D static acquisition of the fetal spine, surface rendering, from posterior insonation, normal case. In terms of spine, the postprocessing allows probably a better discrimination of signals for skin lesions, as shown in Figure 3

although 3D US may be an adjunctive tool, there is scarce evidence that it alters anything in terms of the diagnosis, outcome, or subsequent counseling, regardless the GA.
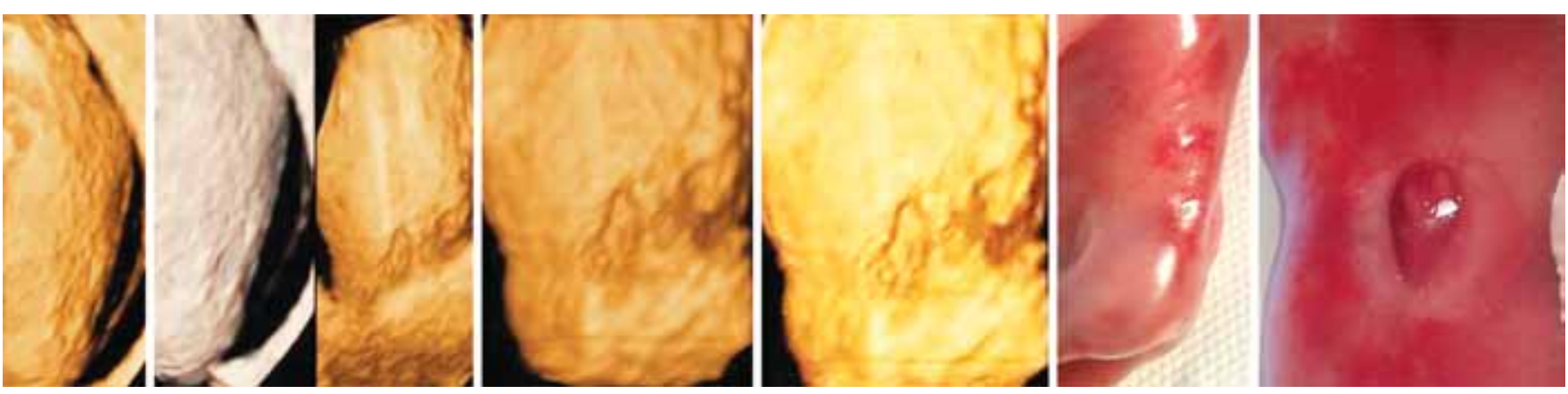

Fig. 3: 3D static acquisition of the fetal spine, surface rendering, from posterior insonation, OSB case. Steps of the postprocessing seen. Correlation with pathologic aspect of the specimen. Studies involving large sample size populations are needed to confirm the true usefulness of 3D US 
In terms of FT OSB, both 3D static volumes of the fetal head (transabdominally or transvaginally acquired) (Fig. 1) and 3D static volumes of the spine (Fig. 2) may be advocated.

The most important advantage of postprocessing the 3D datasets of the fetal head is finding the accurate plane to be interpreted. ${ }^{67}$

\section{DISCUSSION}

There are many important questions that we must find the answer: first of all, should we perform, in general, screening tests in prenatal medicine? Do we need a FT screening protocol for OSB? Or we do not need to search for OSB at all in the FT? Or we do need a diagnosis test in the FT?

If the answer is yes, if we should search for OSB in the FT, should we look at the fetal spine, eventually by the transvaginal route, ${ }^{77}$ or should we look at the intracranial indirect markers ${ }^{61}$ ?

If the fetal head remains the answer for the early detection of OSB, should we use axial or parasagittal planes for screening? ${ }^{60,61,63,65,68-70}$

The first question, probably the most important one, is extremely difficult to answer, due to the conflict between ethical principles and available human and technical resources, especially in developing countries.

Routine obstetric ultrasound testing in general has been shown to be a positive and very much anticipated experience for most patients. On the contrary, women who were told their child might have an anomaly, based on ultrasound findings (either false-positive or true-positive cases) are usually intensely anxious the time interval between the screening ultrasound and the conclusive exam, and even beyond it. ${ }^{78-80}$ The experience itself of waiting for a detailed scan provokes increases in anxiety beyond what pregnant women typically experience. Referral for any highly specialized scan and all specialized prenatal testing are independently associated with increased parental anxiety.

On the other hand, if we decide against offering detailed scans to every pregnant woman, these examinations will be restricted to women that can afford the costs by themselves, and this approach is very near to violating of the principle of justice for all.

Debates have already taken place in regards to whether we need or we do not need a screening tool for OSB in the first trimester. ${ }^{61,77}$

The WHO defines certain criteria for screening tests. ${ }^{81}$ The disease must be of sufficient prevalence and severity and should have a fixed spectrum of symptoms, the screening method should be simple and acceptable, screening should be accurate, confirmation and follow-up should be available, the disease should be treatable and screening should show improved outcome and a positive cost/benefit ratio.

The prenatal diagnosis of OSB fulfills completely the criteria of a target lesion for a screening test. The strongest reason against elaborating a $\mathrm{FT}_{\text {protocol }}{ }^{77}$ is the circumstance that the intrauterine repair of OSB, demonstrated to be efficient in ameliorating the CNS damage, is only technically feasible late in pregnancy, during the second half of the second trimester. ${ }^{82,83}$

For the lifesaving effects of prenatal medicine, in most of the cases a diagnosis early in pregnancy is not mandatory, thus, for continuing pregnancies, it is no disadvantage if diagnosed in the second half of pregnancy.

In case of TOP, the situation is different: there are strong medical and ethical arguments against late TOP. Late TOP includes several risks and is evaluated as being worse than early TOP, because of at least two reasons: in general, maternal pregnancy-involved risks are related to the GA, and so women who continue their pregnancy and terminate it in later stages suffer a greater risk, and the mother-embryo/fetus-relationship will deepen as the pregnancy continues. This will lead to a stronger burden for the mother if she decides for late TOP in consequence of the late detection of a major anomaly.

Because early TOP seems to include less risks and less harm for the women it is comprehensible that women prefer earlier TOP as compared with later.

The offer of an early diagnosis of possible severe anomalies is a tool enhancing the autonomy of the pregnant woman (resources within the healthcare systems are constantly shortened). If autonomy is regarded as an important right in one's life, women should have the right to choose whether to take advantage of prenatal diagnosis or not. If women decide to claim for prenatal medicine, it seems to be part of their right to get all possible screening options offered by prenatal medicine they want to have access to.

There are arguments against the concept of offering a screening test/a detailed anomaly scan to all patients: besides the problem of limited resources in healthcare systems, is the question of detection rate of anomalies in fetuses with relative low-risk.

We have also to prevent the false positive results with the risk of termination of unaffected fetuses, which is an argument to perform detailed scans only in specialized centers in which skill, detection rate and accuracy of the prenatal diagnosis are continuously audited.

Concerning the most efficient approach, meaning to choose between looking at the fetal spine or the fetal brain, transabdominal or transvaginal, in 2D conventional US or in volumetric US, probably only large, prospective, collaborative studies or randomized trials will give us the answer. 
On the other hand we already have proof that the more extended the protocol used, regardless the GA, the lower figures of false-negative and false-positive cases were reported. Thus, we will probably achieve the highest detection rates if using both axial and parasagittal views.

\section{CONCLUSION}

With the advance of both technology and research, early pregnancy screening is becoming ever more sophisticated and more complex. In the near future, the first trimester ultrasound will probably target, beside major chromosomal abnormalities, all isolated major structural anomalies, such as OSB.

The prenatal ultrasound examination is however a highly system-dependent and operator-dependent technique. Using high resolution machines on one hand, and on the other, the operator's knowledge about the normal and pathological fetal first trimester neuroanatomy, natural history of OSB function of the extension and location of the lesion, experience, appropriate technical skills and clinical judgment are of paramount importance for obtaining the correct diagnostic images and for interpretation of the diagnostic images. Therefore, for the time being, local conditions and expertise in individual centers may critically affect the accuracy of the US diagnostic modalities for early OSB diagnosis.

While there are clear benefits to most women receiving early reassurance that their baby is developing as expected, there is no evidence that an earlier prenatal diagnosis has less long-term emotional impact than at later gestations.

Because the first trimester scan information may change radically management of the pregnancy, professionals involved in screening need to recognize and acknowledge the adverse side-effects of such an US scan and should develop the skills necessary to help the parents to understand the concept of screening and the uncertainties inherent to this process.

However, when the technical and available expertise issues will be overcame, the offer of an early diagnosis of all possible severe anomalies, including OSB, will be a tool enhancing the autonomy of the pregnant woman.

\section{REFERENCES}

1. Torloni MR, Vedmedovska N, Merialdi M, Betrán AP, Allen T, González R, Platt LD. Safety of ultrasonography in pregnancy: WHO systematic review of the literature and meta-analysis. Ultrasound Obstet Gynecol 2009;33:599-608.

2. Nicolaides KH. A model for a new pyramid of prenatal care based on the 11 to 13 weeks' assessment. Prenat Diagn 2011; 31:3-6.

3. Nicolaides KH. Screening for fetal aneuploidies at 11 to 13 weeks. Prenat Diagn 2011;31:7-15.
4. Whitlow BJ, Chatzipapas IK, Lazanakis ML, Kadir RA, Economides DL. The value of sonography in early pregnancy for the detection of fetal abnormalities in an unselected population. BJOG 1999;106:929-936.

5. Economides DL, Braithwaite JM. First trimester ultrasonographic diagnosis of fetal structural abnormalities in a low risk population. Br J Obstet Gynaecol 1998;105:53-57.

6. Guariglia L, Rosati P. Transvaginal sonographic detection of embryonicfetal abnormalities in early pregnancy. Obstet Gynecol 2000;96:328-332.

7. Taipale P, Ammala M, Salonen R, Hilesmaa V. Two-stage ultrasonography in screening for fetal anomalies at 13-14 and 18-22 weeks of gestation. Acta Obstet Gynecol Scand 2004; 83:1141-1146.

8. Chen M, Lam YH, Lee CP, Tang MH. Ultrasound screening of fetal structural abnormalities at 12 to 14 weeks in Hong Kong. Prenat Diagn 2004;24:92-97.

9. Souka AP, Pilalis A, Kavalakis I, Antsaklis P, Papantoniou $\mathrm{N}$, Mesogitis S, Antsaklis A. Screening for major structural abnormalities at the 11- to 14-week ultrasound scan. Am J Obstet Gynecol 2006 Feb;194(2):393-396.

10. Becker R, Wegner RD. Detailed screening for fetal anomalies and cardiac defects at the 11-13-week scan. Ultrasound Obstet Gynecol 2006;27:613-618.

11. Cedergren M, Selbing A. Detection of fetal structural abnormalities by an 11-14-week ultrasound dating scan in an unselected Swedish population. Acta Obstet Gynecol Scand 2006;85:912-915.

12. Dane B, Dane C, Sivri D, Kiray M, Cetin A, Yayla M. Ultrasound screening for fetal major abnormalities at 11-14 weeks. Acta Obstet Gynecol Scand 2007;86:666-670.

13. Chen M, Lee CP, Lam YHH, et al. Comparison of nuchal and detailed morphology ultrasound examinations in early pregnancy for fetal structural abnormality screening: a randomized controlled trial. Ultrasound Obstet Gynecol 2008;31:136-146.

14. Oztekin O, Oztekin D, Tinar S, Adibelli Z. Ultrasonographic diagnosis of fetal structural abnormalities in prenatal screening at 11 to 14 weeks. Diagn Interv Radiol 2009;15:221-225.

15. Ebrashy A, El Kateb A, Momtaz M, El Sheikhan A, Aboulghar MM, Ibrahim M, Saad M. 13-14 weeks fetal anatomy scan: a 5-year prospective study. Ultrasound Obstet Gynecol 2010;35:292-296.

16. Syngelaki A, Chelemen T, Dagklis T, Allan L, Nicolaides KH. Challenges in the diagnosis of fetal nonchromosomal abnormalities at 11-13 weeks. Prenat Diagn 2011;31(1):90-102.

17. Iliescu D, Tudorache S, Comanescu A, Antsaklis P, Cotarcea S, Novac L, Cernea N, Antsaklis A. Improved detection rate of structural abnormalities in the first trimester using an extended examination protocol. Ultrasound Obstet Gynecol 2013, Apr 18.

18. Akolekar R, Bower S, Flack N, Bilardo CM, Nicolaides KH. Prediction of miscarriage and stillbirth at 11-13 weeks and the contribution of chorionic villus sampling. Prenat Diagn 2011;31(1):38-45.

19. van Ravenswaaij $R$, Tesselaar-van der Goot M, de Wolf $S$, van Leeuwen-Spruijt M, Visser GHA, Schielen PCJI. Firsttrimester serum PAPP-A and $\mathrm{fB}-\mathrm{hCG}$ concentrations and other maternal characteristics to establish logistic regressionbased predictive rules for adverse pregnancy outcome. Prenat Diagn 2011;31(1):50-57.

20. Beta J, Akolekar R, Ventura W, Syngelaki A, Nicolaides KH. Prediction of spontaneous preterm delivery from maternal 
factors, obstetric history and placental perfusion and function at 11-13 weeks. Prenat Diagn 2011;31(1):75-83.

21. Greco E, Lange A, Ushakov F, Rodriguez Calvo J, Nicolaides KH. Prediction of spontaneous preterm delivery from endocervical length at 11 to 13 weeks. Prenat Diagn 2011; 31(1):84-89.

22. Akolekar R, Syngelaki A, Sarquis R, Zvanca M, Nicolaides $\mathrm{KH}$. Prediction of early, intermediate and late pre-eclampsia from maternal factors, biophysical and biochemical markers at 11-13 weeks. Prenat Diagn 2011;31(1):66-74.

23. Waugh N, Scotland G, McNamee P, et al. Screening for type 2 diabetes: literature review and economic modelling. Health Technol Assess 2007;11(1-125).

24. Nanda S, Savvidou M, Syngelaki A, Akolekar R, Nicolaides $\mathrm{KH}$. Prediction of gestational diabetes mellitus by maternal factors and biomarkers at 11 to 13 weeks. Prenat Diagn 2011 Feb;31(2):135-141.

25. Plasencia W, Garcia R, Pereira S, Akolekar R, Nicolaides KH. Criteria for screening and diagnosis of gestational diabetes mellitus in the first trimester of pregnancy. Fetal Diagn Ther. 2011;30(2):108-115.

26. Karagiannis G, Akolekar R, Sarquis R, Wright D, Nicolaides $\mathrm{KH}$. Prediction of small-for-gestation neonates from biophysical and biochemical markers at 11-13 weeks. Fetal Diagn Ther 2011;29(2):148-154.

27. Poon LC, Karagiannis G, Stratieva V, Syngelaki A, Nicolaides KH. First-trimester prediction of macrosomia. Fetal Diagn Ther 2011;29(2):139-147.

28. Salomon LJ, Alfirevic Z, Bilardo CM, Chalouhi GE, Ghi T, Kagan KO, Lau TK, Papageorghiou AT, Raine-Fenning NJ, Stirnemann J, Suresh S, Tabor A, Timor-Tritsch IE, Toi A, Yeo G. International Society of Ultrasound in Obstetrics. ISUOG practice guidelines: performance of first-trimester fetal ultrasound scan. Ultrasound Obstet Gynecol 2013 Jan;41(1):102-113.

29. National Collaborating Centre for Women's and Children's Health. Antenatal care Routine care for the healthy pregnant woman NICE clinical guideline 62. 2008, Vol. March, http:// www.nice.org.uk/nicemedia/pdf/CG062NICEguideline.pdf.

30. ACOG. Issues Position on First-Trimester Screening Methods. ACOG NEWS RELEASE. June, 2004, http://www.acog.org/ from_home/publications/press_releases/nr06-30-04.cfm.

31. Jacobs AR, Dean G, Wasenda EJ, Porsch LM, Moshier EL, Luthy DA, Paul ME. Late termination of pregnancy for lethal fetal anomalies: a national survey of maternal-fetal medicine specialists. Contraception 2015 Jan;91(1):12-18.

32. Filly RA, Crane JP. Routine obstetric sonography. J Ultrasound Med 2002 Jul;21(7):713-718.

33. Schwarzler P, Senat MV, Holden D, Bernard JP, Masroor T, Ville Y. Feasibility of the second-trimester fetal ultrasound examination in an unselected population at 18,20 or 22 weeks of pregnancy: a randomized trial. Ultrasound Obstet Gynecol 1999;14:92-97.

34. Saltvedt S, Almstrom H, Kublickas M, Valentin L, Grunewald C. Detection of malformations in chromosomally normal fetuses by routine ultrasound at 12 or 18 weeks of gestation-a randomised controlled trial in 39,572 pregnancies. BJOG 2006;113:664-674.

35. Tegnander E, Williams W, Johansen OJ, Blaas HG, Eik-Nes $\mathrm{SH}$. Prenatal detection of heart defects in a non-selected population of 30149 fetuses-detection rates and outcome. Ultrasound Obstet Gynecol 2006;27:252-265.
36. Goldberg JD. Routine screening for fetal anomalies: expectations. Obstet Gynecol Clin North Am 2004;31:35-50.

37. Grandjean $H$, Larroque D, Levi S. The performance of routine ultrasonographic screening of pregnancies in the Eurofetus Study. Am J Obstet Gynecol 1999;181:446-454.

38. RCOG. Ultrasound screening for fetal abnormalities. Report of the RCOG Working Party. London: The Royal College of Obstet Gynaecol 1997.

39. Maguire M, Light A, Kuppermann M, Dalton VK, Steinauer JE, Kerns JL. Grief after second-trimester termination for fetal anomaly: a qualitative study. Contraception 2014 Dec 11. pii: S0010-7824(14)00787-2. doi: 10.1016/j.contraception.2014.11.015. [Epub ahead of print]

40. Romosan G, Henriksson E, Rylander A, Valentin L. Diagnostic performance of routine ultrasound screening for fetal abnormalities in an unselected Swedish population in 20002005. Ultrasound Obstet Gynecol 2009 Nov;34(5):526-533.

41. Bricker L, Garcia J, Henderson J, et al. Ultrasound screening in pregnancy: a systematic review of the clinical effectiveness, costeffectiveness and women's views. Health Technol Assess 2000;4:1-193.

42. Grande M, Arigita M, Borobio V, Jimenez JM, Fernandez S, Borrell A. First-trimester detection of structural abnormalities and the role of aneuploidy markers. Ultrasound Obstet Gynecol 2012 Feb;39(2):157-163.

43. Malinger G, Lerman-Sagie T, Watemberg N, Rotmensch S, Lev D, Glezerman M. A normal second-trimester ultrasound does not exclude intracranial structural pathology. Ultrasound Obstet Gynecol 2002;20:51-56.

44. Simonazzi G, Segata M, Ghi T, Sandri F, Ancora G, Bernardi B, Tani G, Rizzo N, Santini D, Bonasoni P, Pilu G. Accurate neurosonographic prediction of brain injury in the surviving fetus after the death of a monochorionic cotwin. Ultrasound Obstet Gynecol 2006;27:517-521.

45. Ghi T, Simonazzi G, Perolo A, Savelli L, Sandri F, Bernardi B, Santini D, Bovicelli L, Pilu G. Outcome of antenatally diagnosed intracranial hemorrhage: case series and review of the literature. Ultrasound Obstet Gynecol 2003;22:121-130.

46. Ghi T, Brondelli L, Simonazzi G, Valeri B, Santini D, Sandri F, Ancora G, Pilu G. Sonographic demonstration of brain injury in fetuses with severe red blood cell alloimmunization undergoing intrauterine transfusions. Ultrasound Obstet Gynecol 2004;23:428-431.

47. Rintoul NE, Sutton LN, Hubbard AM, Cohen B, Melchionni J, Pasquariello PS, AdzickNS. A new look at myelomeningoceles: functional level, vertebral level, shunting, and the implications for fetal intervention Pediatrics 2002 Mar;109(3):409-413.

48. NHS Fetal Anomaly Screening Programme - Neural tube defects (NTDs): open spina bifida 2012 http://www.ninds. nih.gov/disorders/spina_bifida/detail_spina_bifida.htm

49. Boyd PA, Wellesley DG, De Walle HE, Tenconi R, GarciaMinaur S, Zandwijken GR, Stoll C, Clementi M. Evaluation of the prenatal diagnosis of neural tube defects by fetal ultrasonographic examination in different centres across Europe. J Med Screen 2000;7(4):169-174.

50. Manning SM, Jennings R, Madsen JR. Pathophysiology, prevention and potential treatment of neural tube defects. Ment Retard Dev Disabil Res Rev 2000;6:6-14.

51. Background of Management of Myelomeningocele Study (MOMS). The GWU Biostatistics Center. Retrieved 2012-08-06.

52. Management of Myelomeningocele Study (MOMS) - Full Text View. Clinical Trials.gov. Retrieved 2012-08-06.

53. Mitchell LE, Adzick NS, Melchionne J, Pasquariello PS, Sutton LN, Whitehead AS. Spina bifida. Lancet 2004;364:1885-1895. 
54. CaldarelliM,DiRocco C,La Marca F.Shuntcomplications in the first postoperative year in children with meningomyelocele. Childs Nerv Syst 1996;12:748-754.

55. Sival DA, Begeer JH, Staal-Schreinemachers AL, Vos-Niël JM, Beekhuis JR, Prechtl HF. Perinatal motor behaviour and neurological outcome in spina bifida aperta. Early Hum Dev 1997;50:27-37.

56. Bouchard S, Davey MG, Rintoul NE, Walsh DS, Rorke LB, Adzick NS. Correction of hindbrain herniation and anatomy of the vermis following in utero repair of myelomeningocele in sheep. J Pediatr Surg 2003;38:451-458.

57. Tulipan N, Bruner JP, Hernanz-Schulman M, Lowe LH, Walsh WF, Nickolaus D, Oakes WJ. Effect of intrauterine myelomeningocele repair on central nervous system structure and function. Pediatr Neurosurg 1999;31:183-188.

58. Peake JN, Copp AJ, Shawe J. Knowledge and periconceptional use of folic acid for the prevention of neural tube defects in ethnic communities in the United Kingdom: Systematic review and meta-analysis. Birth Defects Research Part A: Clinical and Molecular Teratology 2013;97:444-451.

59. Sebire NJ, Noble PL, Thorpe-Beeston JG, Snijders RJM, Nicolaides KH. Presence of the 'lemon' sign in fetuses with spina bifida at the 10-14-week scan. Ultrasound Obstet Gynecol 1997;10:403-405.

60. Chaoui R, Benoit B, Mitkowska-Wozniak H, Heling KS, Nicolaides KH. Assessment of intracranial translucency (IT) in the detection of spina bifida at the 11-13 weeks scan. Ultrasound Obstet Gynecol 2009;34:249-252.

61. Chaoui R, Nicolaides KH. Detecting open spina bifida at the 11-13 weeks scan by assessing intracranial translucency and the posterior brain region: mid-sagittal or axial plane? Ultrasound Obstet Gynecol 2011;38:609-612.

62. Egle D, Strobl I, Weiskopf-Schwendinger V, Grubinger E, Kraxner F, Mutz-Dehbalaie IS, Strasak A, Scheier M. Appearance of the fetal posterior fossa at $11+3$ to $13+6$ gestational weeks on transabdominal ultrasound examination. Ultrasound Obstet Gynecol 2011;38:620-624.

63. Lachmann R, Chaoui R, Moratalla J, Picciarelli G, Nicolaides $\mathrm{KH}$. Posterior brain in fetuses with open spina bifida at 11 to 13 weeks. Prenat Diagn 2011;31:103-106.

64. Mangione R, Dhombres F, Lelong N, Amat S, Atoub F, Friszer, S, Khoshnood B, Jouannic JM. Screening for fetal spina bifida at the 11-13 weeks scan using three anatomical features of the posterior brain. Ultrasound Obstet Gynecol 2013;42:416-420.

65. Garcia-Posada R, Eixarch E, Sanz M, Puerto B, Figueras F, Borrell A. Cisterna magna width at 11-13 weeks in the detection of posterior fossa anomalies. Ultrasound Obstet Gynecol 2013;41:515-520.

66. Lachmann R, Picciarelli G, Moratalla J, Greene N, Nicolaides $\mathrm{KH}$. Frontomaxillary facial angle in fetuses with spina bifida at 11-13 weeks' gestation. Ultrasound Obstet Gynecol 2010;36: 268-271.

67. Loureiro T, Ushakov F, Montenegro N, Gielchinsky Y, Nicolaides KH. Cerebral ventricular system in fetuses with open spina bifida at 11-13 weeks' gestation. Ultrasound Obstet Gynecol 2012;39:620-624.

68. Buisson O, De Keersmaecker B, Senat MV, Bernard JP, Moscoso G, Ville Y. Sonographic diagnosis of spina bifida at
12 weeks: heading towards indirect signs. Ultrasound Obstet Gynecol 2002;19:290-292.

69. Ushakov F, Fernandez M, Lesmes Heredia C, Pandya P. OP06.08: 'Crash sign': displacement and deformation of mesencephalon against occipital bone in the diagnosis of spina bifida at 11-13 weeks. Ultrasound Obstet Gynecol 2014; 44:80.

70. Bernard JP, Cuckle HS, Stirnemann JJ, Salomon LJ, Ville Y. Screening for fetal spina bifida by ultrasound examination in the first trimester of pregnancy using fetal biparietal diameter. Am J Obstet Gynecol 2012 Oct;207(4):306.e1-5.

71. Karl K, Benoit B, Entezami M, Heling KS, Chaoui R. Small biparietal diameter in fetuses with spina bifida on 11-13 weeks and midgestation ultrasound. Ultrasound Obstet Gynecol 2012;40:140-144.

72. Khalil A, Coates A, Papageorghiou A, Bhide A, Thilaganathan B. Biparietal diameter at 11-13 weeks' gestation in fetuses with open spina bifida. Ultrasound Obstet Gynecol 2013;42: 409-415.

73. Simon EG, Arthuis CJ, Haddad G, Bertrand P, Perrotin F. A Biparietal/Transverse Abdominal Diameter (BPD/TAD) Ratio $\leq 1$ : a potential hint for open spina bifida at 11-13 weeks scan. Ultrasound Obstet Gynecol 2014 May 10. doi: 10.1002/ uog.13406. [Epub ahead of print]

74. Hernadi L, Torocsik M. Screening for fetal anomalies in the 12th week of pregnancy by transvaginal sonography in an unselected population. Prenat Diagn 1997;17:753-759.

75. D'Ottavio G, Mandruzzato G, Meir YJ, Rustico MA, FischerTamaro L, Conoscenti G. Comparison of first trimester and second trimester screening for fetal anomalies. Ann NY Acad Sci 1998;847:200-209.

76. Bilardo CM, Pajkrt E, de Graaf I, Mol BW, Bleker OP. Outcome of fetuses with enlarged nuchal translucency and normal karyotype. Ultrasound Obstet Gynecol 1998;11:401-406.

77. Gadot Y, Cohen SM, Yagel S. Do we really need a screening test for open spina bifida? Ultrasound Obstet Gynecol 2012; 39:600-601.

78. Leithner K, Maar A, Fischer-Kern M, Hilger E, Löffler-Stastka $\mathrm{H}$, Ponocny-Seliger E. Affective state of women following a prenatal diagnosis: predictors of a negative psychological outcome. Ultrasound Obstet Gynecol 2004;23:240-246.

79. Athanasiadis AP, Polychronou P, Mikos T, Pantazis K, Assimakopoulos E, Tzevelekis F, Bontis JN. Women's expectations and intention to terminate pregnancy in case of abnormal findings at the second trimester level II ultrasound scan. A prospective, questionnaire-based, cross-sectional survey. Fetal Diagn Ther 2009;25(2):255-263.

80. Harpel TS. Fear of the unknown: ultrasound and anxiety about fetal health. Health (London). 2008 Jul;12(3):295-312.

81. Wilson JMG, Jungner G. Principles and practice of screening for disease. WHO Chronicle. World Health Organization: Geneva 1968; p. 26-27.

82. Bruner JP, Tulipan N, Reed G, Davis GH, Bennett K, Luker KS, Dabrowiak ME. Intrauterine repair of spina bifida: preoperative predictors of shunt-dependent hydrocephalus. Am J Obstet Gynecol 2004;190:1305-1312.

83. Fichter MA, Dornseifer U, Henke J, Schneider KT, Kovacs L, Biemer E, Bruner J, Adzick NS, Harrison MR, Papadopulos NA. Fetal spina bifida repair-current trends and prospects of intrauterine neurosurgery. Fetal Diagn Ther 2008;23:271-286. 